\title{
EVOLUTION OF A NEW HYBRID BIO COMPOSITE AND EVALUATION OF ITS MECHANICAL PROPERTIES
}

\author{
AMAN S. PAWAR ${ }^{1} \&$ ABHISHEK GAIKWAD ${ }^{2}$ \\ ${ }^{I}$ Research Scholar, Department of Mechanical Engineering, Shepherd Institute of Engineering and Technology, \\ Sam Higginbottom University of Agriculture, Technology and Sciences, Allahabad, Uttar Pradesh, India \\ ${ }^{2}$ Assistant Professor, Department of Mechanical Engineering, Shepherd Institute of Engineering and Technology, \\ Sam Higginbottom University of Agriculture, Technology and Sciences, Allahabad, Uttar Pradesh, India
}

The objective of this study is to develop a new Bio-composite material to fulfil the demand of public \& minimize the use of various non-biodegradable materials to save our environment \& soil. In future, Bio-composite is going to replace many materials due to its better mechanical properties. In this paper, the focus is on the use of natural and agricultural wastes, which are present in abundance in nature \& whose production can also be increased as per the need. In the present study, bio composite materials were developed, in which Natural fibres i.e. Banana, Sisal, and Wheat Straw fibre were used as reinforcing materials with Epoxy resin CY-230 and Hardener HY-951. In this Study, the mechanical properties such as Flexural, Compression and Impact Strengths of the specimens with different composition were tested and compared. Fabrication of different specimens was done by using hand layout technique. Bio-composite samples were developed with different composition of constituents. Mechanical tests were conducted according to ASTM and ISO standards and their properties were analysed. It has been observed that equal weight percentage of Banana \& Sisal fibers i.e. specimen 22 possess much better mechanical properties.

KEYWORDS: Non-Biodegradable, Natural Fibers, Banana, Sisal, Composites, Epoxy resin \& Hand Layout Technique
\end{abstract}

Received: Apr 18, 2017; Accepted: May 22, 2017; Published: Jun 07, 2017; Paper Id.: IJMPERDJUN201728

\section{INTRODUCTION}

According to food and agricultural organization survey, natural fibers like Banana, Sisal, and Jute etc. are abundantly available in developing countries. Nowadays, natural fibers are an attractive research area, because they are bio-degradable, eco-friendly, abundant, light weight, low density, high toughness and non-abrasive to processing characteristics. In place of plastic, wood and other polymer items and natural fiber composites are well fitted, which are used in housing, construction sector, agricultural items or implements etc. Natural fibers are now even dominating the automotive and sporting industries by its better mechanical properties. Nowadays, natural fibers such as sisal, banana and jute fiber composite materials are replacing the glass and carbon fibers, because of their easy availability and lower cost.

\section{Composites}

A composite material also known as composition material is made from two or more constituent materials, with significantly different physical or chemical properties, that, when combined produces a material with different characteristics from the individual components. The individual components remain separate and distinct within the finished structure. Composites materials consists of one or more discontinuous phases 
combined in a continuous phase. The discontinuous phases are usually harder and stronger than the continuous phases and are called the reinforcements or reinforcing materials, whereas the continuous phase is termed as the matrix, which is more ductile and less hard. The reinforcements strengthen the composite and improve the overall mechanical properties of the matrix.

Table 1: Composition of Some Natural Fibres

\begin{tabular}{|l|c|c|c|c|}
\hline Fibre Type & $\begin{array}{c}\text { Cellulose } \\
\text { Weight (\%) }\end{array}$ & $\begin{array}{c}\text { Hemi-cellulose } \\
\text { Weight (\%) }\end{array}$ & $\begin{array}{c}\text { Lignin } \\
\text { Weight (\%) }\end{array}$ & $\begin{array}{c}\text { Pectin } \\
\text { Weight (\%) }\end{array}$ \\
\hline Sisal & $66-78$ & $10-14$ & $10-14$ & 10 \\
\hline Roselle & $50-55$ & $8-10$ & 18 & 6 \\
\hline Banana & $63-64$ & 19 & 5 & 8 \\
\hline Wheat Straw & 33.7 & 23.9 & 24.2 & 11 \\
\hline Jute & $61.1-71.5$ & $13.6-20.4$ & $12-13$ & 0.2 \\
\hline
\end{tabular}

\section{LITERATURE SURVEY}

Patel et al. [3] evaluated mechanical properties such as tensile and flexural properties of hybrid banana and sisal reinforced epoxy composites they had been employed in combination with plastics. Arpitha et al. [5] investigated the development of the Polymer Composites with natural fibers and fillers as a sustainable alternative material for some engineering applications, particularly in aerospace applications and automobile applications. Ganesan et al. [7] investigated the effects of various natural fibers in a Bio-composite material. Different types of fibers viz sawdust, straw, rice husk and baggasse were used to prepare the samples and mechanical characterization were carried out. Joshi et al. [9] evaluated that natural fibers are emerging as low cost, lightweight and apparently environmentally superior alternatives to glass fibers in composites.

\section{METHODOLOGY}

This section describes the materials and methods used to fabricate the bio-composite materials.

\section{MATERIALS}

- Banana fiber

- Sisal fiber

- Wheat straw

- $\quad \operatorname{Resin}($ CY 230)

- $\quad$ Hardener (HY 951)

\section{Banana Fiber}

Banana is the second largest produced fruit after citrus, contributing about $16 \%$ of the world's total fruit production. India is largest producer of banana contributing to $27 \%$ of world's banana production. The banana fibers are extracted from the pseudo stem of the banana plant (Musa species). These are growing up to 5-10 feet depending upon the region and climatic conditions. The fibers are located at the outer sheath of the stalk. The qualified stalk of the plant is cut to a length of $100 \mathrm{~cm}$ and its outer sheath is removed. Then, these sections are crushed between two roller drums with scraping blades at its circumference to remove the pulpy material between the fibers. The process of stripping the fibers 
from the stalk is known as extraction. Fiber can be obtained from whole banana plant. Banana fiber is a best fiber with relatively good mechanical properties due to its high alpha cellulose and low lignin percentage. For this study, banana fiber has been purchased from Go green Products Chennai, Tamil Nadu.

\section{Sisal Fiber}

Sisal fiber is extracted from the leaves of the plant Agave sisalana which is widely cultivated in the Western Hemisphere, Africa and Asia. These plants consist of sword shaped leaves of normally $1.5 \mathrm{~m}$ length and a typical plant produces around 150 leaves during its life span of 6 years. It contains about 500-800 fibers, which are normally used to make ropes, carpets etc. The matured leaves standing at an angle of more than 45 to the upright of the plant are cut. The next stage in which the leaves are initially crushed by the rollers of rounded knife edges followed by repetitive beaten is called decortication. Finally, the fibers are dried in sunlight for 3-4 days after washing them in clean water to remove the dusts and unwanted contents in it. Fibre for the study has been procured from Go green Products Chennai, Tamil Nadu.

\section{Wheat Straw}

Straw is an agricultural by-product; the dry stalks of cereal plants, after the grain and chaff have been removed. It can be considered as waste material or left over the harvesting of crops. It was obtained from wheat plant after harvesting of crop, the process involves called as threshing in which the threshing machine separate grain and straw. Straw is light in weight, $100 \%$ bio-degradable, eco-friendly and easily available at locally agricultural field of a farmer.

\section{Resin (CY 230):}

Epoxy resin (araldite) CY-230 is a liquid solvent free epoxy resin. It has versatile applications in technical and industrial application. Curing takes place at room temperature and atmospheric pressure after addition of hardener. It can be coloured easily. It can be odourless, tasteless and completely non-toxic. In the present investigation, CY- 230 was purchased from Singhal Chemical Corporation, Meerut.

\section{Hardener (hy 951):}

Hardener (HY-951) acts as catalyst for resin. Hardener is a yellowish-green liquid, which is resistant from chemical attack. Hardener has been used as curing agent in the industries. Hardener HY 951 purchased from Singhal Chemical Corporation, Meerut.

\section{Preparation of Specimen for Mechanical Tests}

All the specimens are prepared by simply hand layout technique in which, an open mould is used to fabricate a composite material. The specimens are prepared according to ASTM and ISO standard for Flexural, Compressive \& Impact tests, respectively. Hand lay-up technique is the simplest method of composite processing. The infrastructural requirement for this method is also minimal. The processing steps are quite simple.

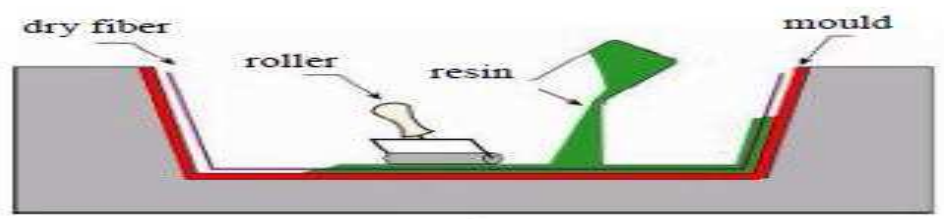

Figure 1: Hand Layout Technique used for Fabrication of Composite 
Table 2: Composition of Different Specimens for Flexural, Compressive and Impact Test (Total Weight Percent of Specimen-: Resin + Hardener=60\% \& Fibres=40\%)

\begin{tabular}{|c|c|c|c|c|c|}
\hline SPECIMEN & $\begin{array}{l}\text { EPOXY RESIN } \\
(\% \text { \& gm })\end{array}$ & $\begin{array}{l}\text { HARDENER } \\
\text { (\% \& gm })\end{array}$ & $\begin{array}{l}\text { BANANA FIBER } \\
(\% \& \text { gm })\end{array}$ & $\begin{array}{c}\text { SISAL FIBER } \\
(\% \& \mathrm{gm})\end{array}$ & $\begin{array}{l}\text { WHEAT STRAW } \\
(\% \text { \& gm })\end{array}$ \\
\hline E1 & $55 \& 38$ & $5 \& 4$ & $12 \& 8.4$ & $20 \& 14$ & $8 \& 5.6$ \\
\hline E2 & $55 \& 38$ & $5 \& 4$ & $20 \& 14$ & $20 \& 14$ & - \\
\hline E3 & $55 \& 38$ & $5 \& 4$ & $20 \& 14$ & $12 \& 8.4$ & $8 \& 5.6$ \\
\hline
\end{tabular}

\section{TEST PROCEDURE}

Though there are number of mechanical tests, which are necessary to determine the suitability of a material, the following important tests have been performed in the present study:

- Flexural strength test

- Compression test

- Impact test

Different specimens for Flexural testing, Compression testing \& Impact testing were made according to ASTM \& ISO standard and as per directed by different testing machine.

\section{Flexural Test}

Flexural testing is performed to determine the rigidity of the hybrid fiber composites, and it is done under bending loads. Three point bending flexural tests are usually used in the composite material tests, because the sample preparations are very simple. For Flexural test rectangular specimens were cut out from the casting as per ASTM D790 standard which is best with respect to the UTM (universal testing machine).

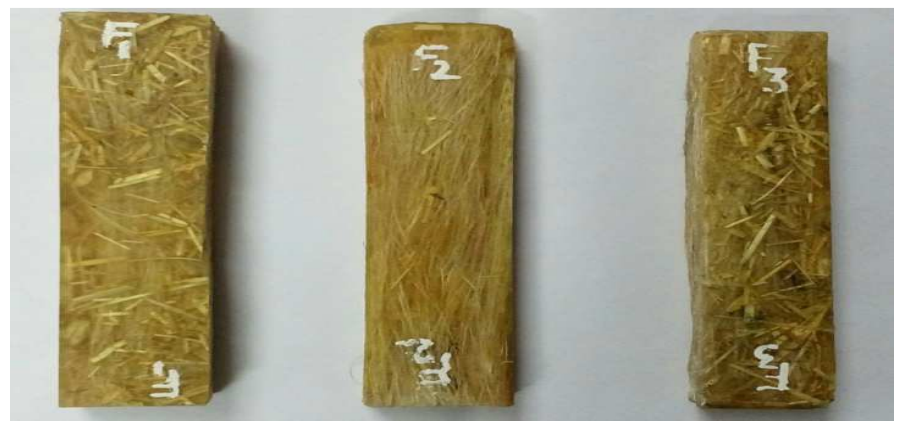

Figure 2: Flexural Test Specimen

\section{Compression Test}

In this test, specimens are made into circular shape. Specimen should be circular and its length to diameter ratio should be less than one. All the compression tests of casted hybrid composites were conducted using $200 \mathrm{kN}$ servo hydraulic UTM machine (model 2012, ANEKY make). Circular specimen used for compression test, were prepared by casting as per ISO -1708 (1960) standard. 


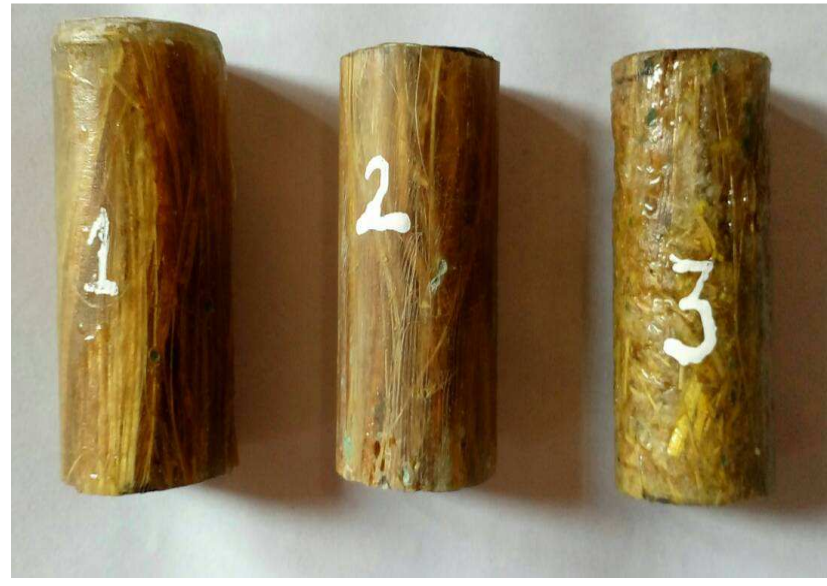

Figure 3: Compression Test Specimen

\section{Impact Test}

Izod impact testing is a method of determining the impact resistance of composites. In impact test, an arm held at a specific height is released during the testing. The arm impacted on the sample and breaks the sample. The energy absorbed by the material before it fractured is recorded, which is used to measure the toughness and ductility of the material. A $2 \mathrm{~mm}$ deep notch has been made at an angle of $45^{\circ}$ with a notch cutter machine. For Impact test, specimens were cut out from the casting, according to ASTM D256 standard for Izod impact test.

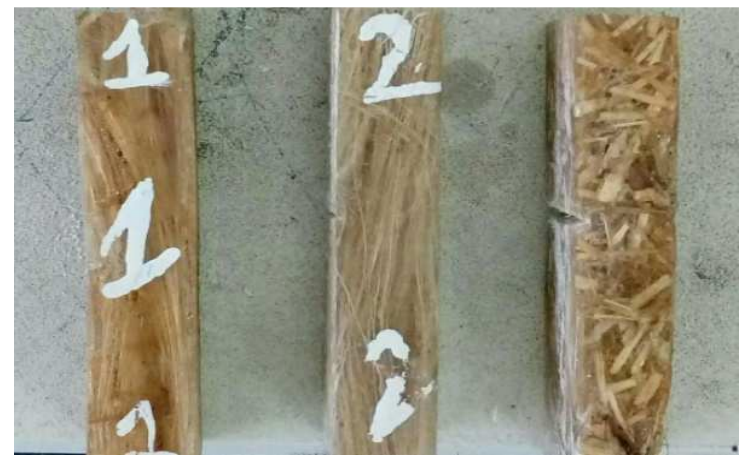

Figure 4: Impact Test Specimen

\section{RESULTS AND DISCUSSIONS}

In this section, the evaluation of composite material samples (E1, E2 and E3), which has been fabricated for mechanical test i.e. flexural, compression and impact are discussed. The graphical representation of flexural, compression $\&$ impact tests are given in figure 5, 6 and 7, respectively.

\section{Flexural Strength}

Table 3: Flexural Strength of Different Samples

\begin{tabular}{|l|c|c|c|c|c|}
\hline Experiment & $\begin{array}{c}\text { Gauge Length } \\
(\mathbf{m m})\end{array}$ & Width $(\mathbf{m m})$ & $\begin{array}{c}\text { Thickness } \\
(\mathbf{m m})\end{array}$ & $\begin{array}{c}\text { Load } \\
(\mathbf{N})\end{array}$ & $\begin{array}{c}\text { Flexural } \\
\text { Strength }\left(\mathbf{N} / \mathbf{m m}^{\mathbf{2}}\right)\end{array}$ \\
\hline E1 & 100 & 20 & 10 & 522.75 & 39.20 \\
\hline E2 & 100 & 20 & 10 & 1482 & 111.15 \\
\hline E3 & 100 & 20 & 10 & 916.25 & 68.71 \\
\hline
\end{tabular}




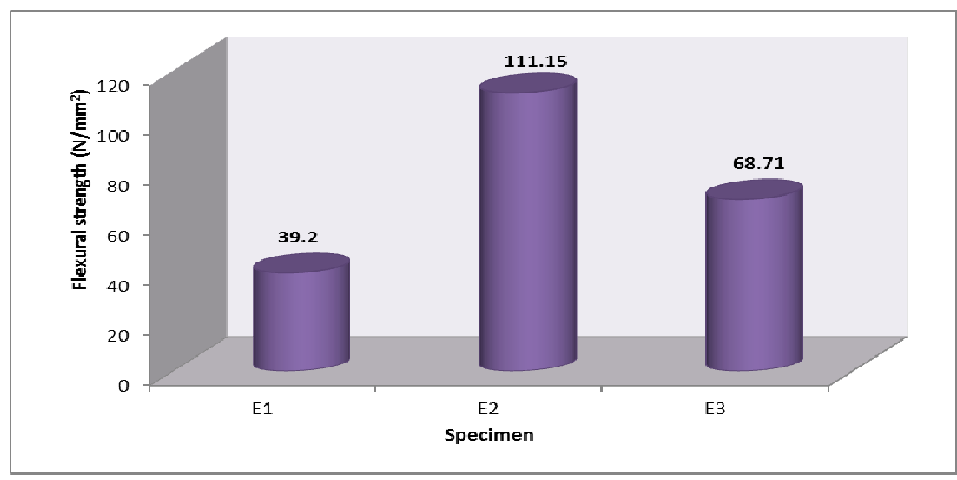

Figure 5: Graphical Representation of Flexural Strength $\left(\mathbf{n} / \mathbf{m m}^{2}\right)$ on Different Specimen

Compressive Strength

Table 4: Compressive Strength of Different Samples

\begin{tabular}{|l|c|c|c|c|c|}
\hline Experiment & Width (mm) & $\begin{array}{c}\text { Gauge } \\
\text { Length }(\mathbf{m m})\end{array}$ & Area $\left(\mathbf{m m}^{\mathbf{2}}\right)$ & Load (N) & $\begin{array}{c}\text { Compressive } \\
\text { Strength(N/mm }\end{array}$ \\
\hline E1 & 30 & 60 & 707.142 & 31500 & 44.54551 \\
\hline E2 & 30 & 60 & 707.142 & 43800 & 61.93947 \\
\hline E3 & 30 & 60 & 707.142 & 38200 & 54.02027 \\
\hline
\end{tabular}

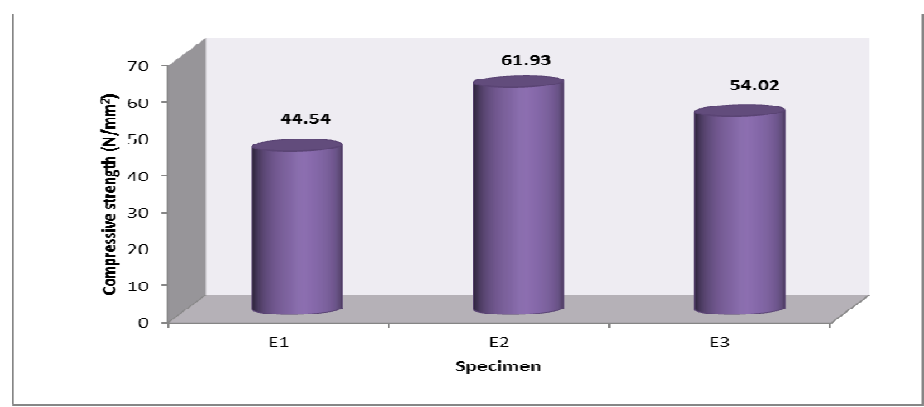

Figure 6: Graphical Representation of Compressive Strength $\left(\mathrm{n} / \mathrm{mm}^{2}\right)$ on Different Specimen Impact Strength

Table 5: Impact Strength of Different Samples

\begin{tabular}{|c|c|c|c|}
\hline Specimen & E1 & E2 & E3 \\
\hline Impact Strength $(\mathbf{J} / \mathbf{m})$ & 79.9 & 100.5 & 89.9 \\
\hline
\end{tabular}

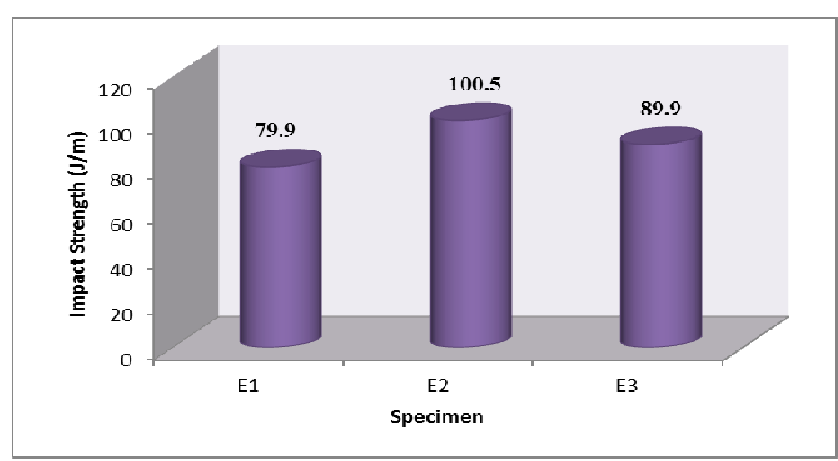

Figure 7: Graphical Representation of Impact Strength $(j / m)$ on Different Specimen 


\section{CONCLUSIONS}

In the present study, the evaluation of mechanical properties of natural fiber rein-forced composite has been done, and the following conclusion have been drwan from. The maximum flexural strength is $111.15 \mathrm{~N} / \mathrm{mm}^{2}$, maximum compression strength is $61.93 \mathrm{~N} / \mathrm{mm}^{2}$ and maximum impact strength recorded is $100.5 \mathrm{~J} / \mathrm{m}$ of E2 specimen, which contain $20 \%$ of banana fiber \& $20 \%$ of sisal fiber of the total wt $\%$ of the specimen fabricated. It is suggested from the experimental study that specimen E2 can bear up the higher loads when compared to the other specimen combinations, and can be used as an alternate materials for usual uses. The developed composites are a good substitute for a number of wood based products and non biogradable material. They have lot of advantages like low density, low price, recyclable, biodegradable, low abrasive wear, and environment friendly.

\section{REFERENCES}

1. Hemant Patel, Prof. AshishParkhe, Dr P.K. Shrama. 2016. Mechanical Behaviors Of Banana And Sisal Hybrid Composites Reinforced with Epoxy Resin. International Journal of Research - GRANTHAALAYAH, Vol. 4, Issue 1, pp. 206-216.

2. Arpitha G R, Sanjay M R, L LaxmanaNaik, B Yogesha. 2014. Mechanical Properties of Epoxy Based Hybrid Composites Reinforced with Sisal/SIC/Glass Fibers. International Journal of Engineering Research and General Science, Vol. 2, Issue 5, pp. 398-405.

3. G. U. Raju, S. Kumarapp, V. N. Gaitonde. 2012. Mechanical and physical characterization of agricultural waste reinforced polymer composites. J. Mater. Environ. Sci., Vol.3, Issue 5, pp-907-916.

4. S.V. Joshi, L.T. Drzal, A.K. Mohanty, S. Arora. 2004. Are natural fiber composites environmentally superior to glass fiberreinforced composites.Science direct, Vol. 35, pp. 371-376.

5. AjithGopinath, SenthilKumar.M, Elayaperumal. 2014. Experimental Investigations on Mechanical Properties Of Jute Fiber Reinforced Composites with Polyester and Epoxy Resin Matrices. Science Direct, Procedia Engineering, Vol.9, pp. 20522063.

6. ManeeshTewari, V. K. Singh, P. C. Gopeand Arun K. Chaudhary. Evaluation of Mechanical Properties of Bagasse-Glass Fiber Reinforced Composite.J. Mater. Environ. Sci., Vol.3, Issue 1, pp. 171-184.

7. L LaxmanaNaik, K Gopalakrishna, B Yogesha.2015.Review on Mechanical Properties of Sisal and Banana Reinforced Composites. International Journal of Engineering Research and General Science, Vol 3, Issue 5, pp. 176-179.

8. Biswas, Sandhyarani, Satapathy, Alok and Patnaik. 2005. Effect of ceramic fillers on mechanical properties of bamboo fiber reinforced epoxy composites. Department of mechanical engineering, NIT, Rourkela.

9. Chowdhury, D. 2010. Study on mechanical behaviour of wood dust filled polymer composites (B.Thesis). Dept of mechanical engineering, NIT, Roukela.

10. Dr. Gouda, A. T., Jagadish, S. P., Dr. Dinesh, K. R., Gouda, V. and Dr. Prashanth, N. 2014. Wear study on hybrid natural fiber polymer composite materials used as orthopaedic implants. International Journal of Recent Development in Engineering and Technology, Vol. 3, Issue 1, pp. 25-33. 
